\title{
Mortality among drug addicts in Greater London
}

\author{
A HAMID GHODSE, M SHEEHAN, B STEVENS, C TAYLOR, G EDWARDS
}

British Medical fournal, 1978, 2, 1742-1744

\section{Summary and conclusions}

During January 1970 to December 1974, 134 deaths in people aged 10-50 years investigated by coroners in Greater London were recorded as being due to drug addiction. Over three-quarters of the addicts were under 30 , and $105(78 \%)$ were male; $55(41 \%)$ were unknown to the Home Office. Barbiturate overdose accounted for over half of the deaths, though two-thirds of these were in people registered as addicts to notifiable drugs.

Since the Home Office index is concerned with addiction to one class of drugs only, it fails to reflect accurately the prevalence of all serious forms of addiction. Owing to the continuous change in drug-taking behaviour, however, probably no one method of assessment can provide a complete picture, and thus complementary research methods are essential.

\section{Introduction}

Drug addicts are likely to die young and from a multiplicity of causes. ${ }^{12}$ Estimates of mortality vary with the research methods used, ranging from 20 to 28 times the rate expected for a comparable, non-addict population and increasing from about $2 \%$ at one year to some $9 \%$ after six years of known addiction. ${ }^{1-4}$ Such information has usually been collected by personal contact with a particular cohort of addicts, often supplemented by case records, or by larger surveys based on the official Home Office index of notified addicts. ${ }^{5}$ ' The Home Office index, however, records only those addicted to notifiable drugs (opiates and cocaine), its completeness even within these boundaries having been questioned, ${ }^{78}$ and studies from drug treatment clinics are concerned with segments of the same notified population. Thus now that multiple drug misuse is the general rule this emphasis on dependence on one group of drugs alone seems outdated and illogical.

We have therefore attempted to count all deaths among addicts notified to coroners in Greater London during five years regardless of the cause of death recorded and category of drugs of addiction. Since the coroner must be informed of any death arising from the use of drugs, whether occurring during treatment or as a result of mishap, abuse, or addiction, such a survey should provide accurate information on the number of addicts who die in a given period and whose death is in any way related to drug-taking. Deaths recorded as "death due to addiction" were analysed in detail and the findings checked against the Home Office index.

By definition the information we obtained was about the most serious forms of addiction-that is, in which the addicts diedwhether the drugs were notifiable or not. Furthermore, the data could be used as a check on the notification system to see

\section{St George's Hospital, London SW17 0QT}

A HAMID GHODSE, MD, PHD, consultant psychiatrist

Addiction Research Unit, Institute of Psychiatry, London SE5 M SHEEHAN, MSOcsc, research administrator

B STEVENS, BA, PHD, research worker

C TAYLOR, MSC, statistician

G EDWARDS, DM, MRCPSYCH, consultant psychiatrist and director

what proportion of those who died were already known to the Home Office. Finally, just as analgesic nephropathy and alcoholic cirrhosis have proved to be useful in epidemiological studies of dependence on these two classes of drugs, ${ }^{910}$ so detailed information on deaths among addicts may contribute to knowledge of the prevalence of addiction, and particularly its serious forms.

\section{Method}

The records of seven of the eight coroners' courts in Greater London for the period January 1970 to December 1974 were searched for deaths in people aged 10-50 years in which the verdict was "death due to drug addiction." We were also permitted access to the records of five such cases that occurred during the same period in Croydon (the eighth area). A $10 \%$ systematic simple random sample of all unnatural deaths during the period was also obtained from the court registers, the same data abstraction form for drug information being used as that for the main sample. This permitted analyses of all deaths whatever the inquest finding so that an approximation could be made of the number of addicts dying from causes other than their addiction.

We examined the Home Office index of dead and current addicts to see how many of the addicts identified in the survey were known to the Home Office. The Home Office obtains its data from various sources-for example, drug clinics, hospitals, coroners, and newspapers-although there is no obligation for any agency to inform the Home Office of an addict's death. The information obtained from inquest material, including, when available, any clinical history, necropsy data, and toxicological results, were transferred to a specially designed precoded inventory for statistical analysis.

\section{Results}

During the survey period 134 deaths were recorded by coroners as being due to drug addiction. Table I gives the yearly incidence of cases. The $10 \%$ random sample contained a further 14 addicts (representing 140 in the whole population) whose cause of death was not apparently directly related to their addiction. Thus an estimated $274 \pm 75$ addicts ( $95 \%$ confidence interval for Poisson sampling) died during the five years.

TABLE I-Yearly incidence of deaths due to drug addiction in people aged 10-50 years recorded by coroners in Greater London

\begin{tabular}{|c|c|c|c|c|c|}
\hline $\begin{array}{l}\text { Year } \\
\text { No }(\%) \text { of addicts }\end{array}$ & $\begin{array}{c}1970 \\
21(15 \cdot 7)\end{array}$ & $\begin{array}{c}1971 \\
25(18 \cdot 7)\end{array}$ & $\begin{array}{c}1972 \\
40(29 \cdot 9)\end{array}$ & $\begin{array}{c}1973 \\
22(16 \cdot 4)\end{array}$ & $\begin{array}{c}1974 \\
26(19 \cdot 4)\end{array}$ \\
\hline
\end{tabular}

Notification and Home Office figures-Of the 134 addicts whose death was officially attributed to drug addiction, $79(59 \%)$ were known to the Home Office and $55(41 \%)$ were not. No statistically significant differences were detected between these two groups except where specifically mentioned below. Of the 14 additional addicts who died of causes apparently unrelated to their addiction, 10 were not known to the Home Office. The small number of cases (14) identified in the random sample precluded statistical analysis. According to the Home Office index, 164 addicts in the age group 10-50 years died in London during the period under survey.

Sex and age-Of the 134 addicts in the main sample, $105(78 \%$ ) were male and $29(22 \%)$ female. Over three-quarters were under 30 (table II). Of the 13 addicts aged under 20 at the time of death, 11 were not known to the Home Office; this was a significantly greater proportion than among those over $20\left(\chi^{2}=3.92 ; \mathrm{P}<0.05\right)$.

Agents causing death-Table III lists the primary agents responsible for death in the 134 cases. This information was compiled from the 
TABLE II-Age distribution of addicts who died as a result of addiction

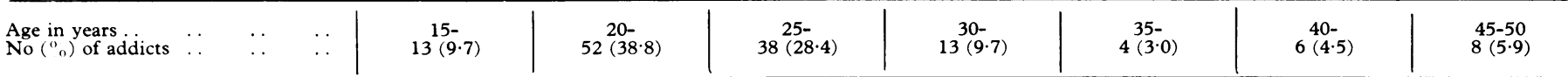

pathologists' reports, which were based on toxicological analysis, when available, of postmortem material. A secondary drug was identified in 74 cases, and three or more drugs in $38\left(28^{\circ}\right)$. Seventy-one deaths $\left(53^{\circ}\right)$ were primarily attributable to barbiturate overdose, and in 44 $(62 \%)$ of these the addicts were known to the Home Office for opiate addiction. Moreover, of the 29 female addicts who died during the five years, 22 did so as a result of barbiturate overdose; barbiturates were detected at necropsy in $24(83 \%)$ of the female addicts and 48 $(46 \%)$ of the male addicts $\left(\chi^{2}=11.94 ; \mathrm{P}<0.001\right)$. Table III gives the proportions of deaths among addicts who were not known to the Home Office.

Physical conditions causing death-Apart from infectious complications of non-sterile injections ( 18 cases $; 13^{\circ}$ ) , all physical conditions causing death-for example, asphyxia, cerebral anoxia-were probably attributable to drug overdose (table IV). Marks of injection were reported in $109(81 \%)$ cases.

Place of death-Fifty-one addicts $\left(38^{\circ}{ }_{0}\right)$ died at home, $26(19 \%)$ in an open or derelict place, and $22\left(16^{\circ}{ }_{0}\right)$ in hospital. The rest died in communes, friends' flats, or hotels.

Materials found at scene of death-In 97 cases $(72 \%)$ syringes, needles, or drugs were found at the scene of death. Drugs alone were found in $29\left(22^{\circ}{ }_{0}\right)$ cases, but in $68\left(51^{\circ}{ }_{0}\right)$ injection equipment was present, together with drugs in $57\left(43^{\circ}\right.$ ) of these instances.

Drug history-Whenever possible details of the drugs used during the addiction careers of the addicts were extracted from the coroners' records (table $\mathrm{V}$ ). Twice as many addicts had obtained barbiturates illicitly as had done so legally, and according to the records the illicit use of methadone was comparatively small. Eleven of the 59 addicts $\left(19^{\circ}{ }_{0}\right)$ who had had opiates other than methadone prescribed for them were not known to the Home Office, and neither were 12 of the 64 addicts $\left(19^{\circ}\right)$ to whom methadone had been prescribed at some time. Four addicts who had received prescriptions for both heroin and methadone had escaped notification.

Social history-Marital state was ascertained in 108 cases: 65 of the addicts $\left(60^{\circ}{ }_{0}\right)$ had never been married, $30\left(28^{\circ}{ }_{0}\right)$ were married at the

TABLE III-Agents causing death of the 134 addicts

\begin{tabular}{|c|c|c|c|c|}
\hline & \multicolumn{2}{|c|}{ Agents detected at necropsy } & \multicolumn{2}{|c|}{ Primary cause of death } \\
\hline & $\begin{array}{l}\text { No ("..) of } \\
\text { cases }\end{array}$ & $\begin{array}{l}\text { " } " \text { of cases } \\
\text { not known to } \\
\text { Home Office }\end{array}$ & $\begin{array}{l}\text { No }(", \ldots) \text { of } \\
\text { cases* }\end{array}$ & $\begin{array}{l}0 \text { of cases } \\
\text { not known to } \\
\text { Home Office }\end{array}$ \\
\hline $\begin{array}{l}\text { Opiates other than } \\
\text { methadone } . . \\
\text { Methadone } \\
\text { Barbiturates } \\
\text { Other drugs } \\
\text { Alcohol }\end{array}$ & $\begin{array}{l}49(37) \\
44(33) \\
72(54) \\
34(25) \\
20(15)\end{array}$ & $\begin{array}{l}39 \\
25 \\
38 \\
55 \\
70\end{array}$ & $\begin{array}{c}20(15) \\
18(13) \\
71(53) \\
9(7)\end{array}$ & $\begin{array}{l}55 \\
22 \\
38 \\
44\end{array}$ \\
\hline
\end{tabular}

*In 16 cases $\left(12^{\prime \prime}\right)$ primary agent causing death was not ascertained, although an opiate was found in 10 cases and alcohol in further three.

TABLE IV-Physical conditions causing death of the 134 addicts

Asphyxia due to postural
causes inhalation of vomit
Bronchopneumonia
Cerebral anoxia

No $\left({ }_{0}^{\circ}\right)$
of
addicts
$48(35 \cdot 8)$
$22(16 \cdot 4)$
$1(0 \cdot 7)$

Endocarditis
Septicaemia

Hepatitis

Cause not determined

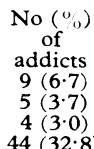

TABLE $\mathrm{v}-L i c i t$ and illicit use of drugs by the 134 addicts who died as a result of addiction. Figures are numbers of addicts (percentages in parentheses)

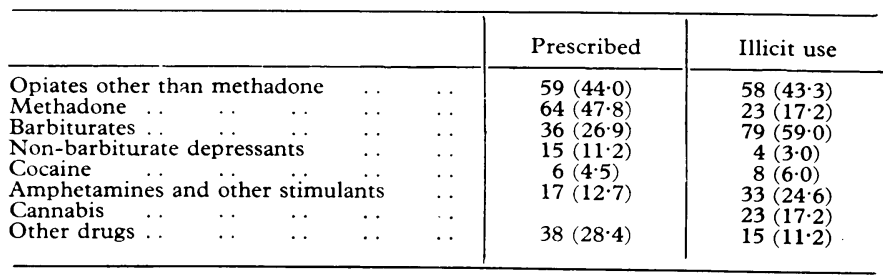

time of death, $11(10 \%)$ were separated, and $2(2 \%)$ were widowed. Employment was recorded in 125 cases : 83 (66\%) were unemployed, $24(19 \%)$ had a regular job, $16(13 \%)$ were in irregular employment, and $2(2 \%)$ were students.

\section{Discussion}

Our findings highlight some of the serious problems arising from current patterns of drug addiction. During the five years covered by the survey 134 deaths in Greater London were recorded by coroners as being due to drug addiction, and probably there were about 140 other addicts whose deaths were recorded differently. The overall figure, though only approximate, may be an underestimate because one coroner's court was unable to participate fully in the study.

That $55(41 \%)$ of the 134 addicts in the main sample were not known to the Home Office is not altogether surprising. The comparable figure among 395 drug-dependent patients in a survey of London accident and ernergency departments was at least $57 \%,{ }^{7}$ although Gardner in a study in London coroners' courts found that only two out of 67 addicts were not known to the Home Office. ${ }^{11}$ The official index is concerned only with notifiable drugs, so possibly some of those who died had never used those drugs. More probably, however, the observed failure ${ }^{6}$ by doctors to notify addicts to the Home Office is at least partially responsible for the inaccuracy of the index ${ }^{8}$ as nearly $20 \%$ of those for whom opiates had been prescribed at some time had not been notified.

Although the Home Office index may be a numerical underestimate, the demographic data we obtained were similar to those described by Grimes in his survey of 3634 addicts notified by hospitals during $1968-73 .{ }^{6}$ During that period $249(7 \%)$ addicts died, of whom $80^{\circ}$ o were male, and this proportion is almost identical with that which we found. The sex ratio was also similar to that found among all new notifications, ${ }^{12}$ although in the London casualty survey the male to female ratio of drugdependent patients was about equal, ${ }^{7}$ and in Brighton Pirrie reported that out of eight addicts who died, four were female. ${ }^{13}$ The age distribution of addicts in our study was also similar to that described by Grimes and in the London casualty survey. ${ }^{6}$

The use of barbiturates by drug addicts is well recognised and was responsible for over half of the deaths in our series. Nearly two-thirds of the addicts were known to the Home Office, presumably because of addiction to a notifiable drug, and yet it was not the notifiable "hard" drug that caused their death.

So far as narcotics are concerned it is now general drug-clinic policy to prescribe methadone to addicts in preference to heroin. There was evidence of this practice in the present survey, in that methadone had been prescribed to more addicts than had heroin or other opiates. Methadone, however, was used illicitly by a much smaller proportion of addicts $(17 \%)$ than were other opiates $(43 \%)$, and much higher proportions of those in whom methadone was detected post mortem $(75 \%)$ and of those in whom it was the main cause of death $\left(78^{\circ} \%\right)$ had been notified to the Home Office than was the case for those who took opiates other than methadone. Thus apparently there was relatively little spill-over from clinic prescriptions of methadone to the black market, presumably because of careful and frugal prescribing. The same may be true of heroin and other opiates prescribed, but it is difficult to be sure because of the alternative supply of imported heroin, which we did not attempt to identify separately.

One of the main values of an index of addicts is to serve as an epidemiological monitor, but this function cannot be fulfilled if 
the index is incomplete, and at present it probably provides only an underestimate of opiate use. One way in which the index might be modified to reflect more accurately the prevalence of all the serious forms of drug addiction would be to extend compulsory notification to include all self-injectors. Although this might have improved the accuracy of the index at the time of our survey (over $80 \%$ of addicts had injection marks), there is evidence that self-injection is becoming less common. ${ }^{14}$ This continuous, rapid change in the pattern of drug-taking behaviour makes any rigid system of notification, particularly one dependent on doctor-participation, unlikely to succeed in isolation as an epidemiological monitor, and it is in this context that the value of a survey such as ours in coroners' courts can be most easily appreciated. Repeated surveys not only in coroners' courts but in prisons, clinics, and accident and emergency departments would be a much more sensitive way to monitor drug misuse and its morbidity and mortality.

Nevertheless, a central, integrated record of all notifications and of the results of different surveys is clearly of value, and the Home Office index can fulfil this role. Moreover, even in the present study the figures suggest that some deaths of addicts in London were known to the Home Office but had not been notified to a coroner, perhaps because the addict was not taking drugs at the time of death. Again, this emphasises that no one technique is ever likely to provide all the answers and that complementary research methods are essential.
We should like to thank the Home Office officials and HM Coroners in Greater London for their help and advice and for permitting access to their records. We also thank Mr D G Turner, Mr H B Spear, and Miss J Mott for their comments.

This study was supported by funds from the Department of Health and Social Security and the Medical Research Council.

\section{References}

1 James, I P, British fournal of Addiction, 1967, 62, 391.

2 Bewley, T H, Ben-Arie, O, and James, I P, British Medical fournal, $1968,1,725$.

3 Bewley, T H, James, I P, and LeFevre, C, International fournal of the Addictions, 1972, 7, 597.

4 Thorley, A, Oppenheimer, E, and Stimson, G V, British fournal of Psychiatry, 1977, 130, 565.

5 Bewley, T H, and Ben-Arie, O, British Medical fournal, 1968, 1, 727.

- Grimes, J A, Drug Dependence Study: A Survey of Drug Addicts Attending for Treatment. Statistics and Research Division, DHSS, 1977.

7 Ghodse, A, H, British fournal of Psychiatry, 1977, 131, 273.

${ }^{8}$ Ghodse, A H, British Medical fournal, 1977, 1, 1381.

- Murray, R M, Scottish Medical fournal, 1972, 17, 393.

10 Jellinek, E M, Quarterly fournal of Studies on Alcohol, 1959, 20, 261.

11 Gardner, R, Lancet, 1970, 2, 650.

12 Bransby, E R, Curley, G, and Kotulanska, M, Health Trends, 1973, 5, 17.

13 Pirrie, G D, British Fournal of Addiction, 1977, 72, 365.

14 Rathod, N H, British fournal of Addiction, 1972, 67, 113.

(Accepted 25 October 1978)

\title{
Guar crispbread in the diabetic diet
}

\author{
DAVID J A JENKINS, THOMAS M S WOLEVER, RICHARD NINEHAM, RODNEY TAYLOR, \\ GEOFFREY L METZ, SUSAN BACON, T DEREK R HOCKADAY
}

British Medical fournal, 1978, 2, 1744-1746

\section{Summary and conclusions}

Nine diabetic patients who were receiving various treatments supplemented their normal home diets (two patients) or metabolic ward diets (seven patients) with guar crispbread for five days. Their mean urinary glucose excretion fell significantly by $38 \%$ during the last two days. A significant fall in fasting blood glucose concentration of $1.1 \pm 0.4 \mathrm{mmol} / 1(19.8 \pm 7.2 \mathrm{mg} / 100 \mathrm{ml})$ was seen only in those who took guar after the control period. Over eight weeks' treatment insulin dosage was reduced by $21 \%$ in five patients, and home testing showed that glycosuria was reduced by $68 \%$ in six patients.

\footnotetext{
Radcliffe Infirmary, Oxford

DAVID J A JENKINS, DM, research associate, department of the regius professor of medicine

T DEREK R HOCKADAY, DPHIL, FRCP, consultant physician

University Laboratory of Physiology, Oxford

THOMAS M S WOLEVER, BA, research fellow

RICHARD NINEHAM, BA, research scholar

Department of Gastroenterology, Central Middlesex Hospital, London NW10

RODNEY TAYLOR, MRCP, honorary senior registrar

GEOFFREY L METZ, FRACP, senior registrar

Metabolic Unit, Nuffield Orthopaedic Centre, Oxford

SUSAN BACON, SRD, senior dietitian
}

Guar crispbread is likely to be a useful adjunct to diabetic treatment irrespective of the type of treatment or insulin dosage used.

\section{Introduction}

Certain forms of dietary fibre (unabsorbable plant polysaccharides) have been used successfully to treat diabetes ${ }^{1-3}$ and have permitted withdrawal of insulin or reduction of the dose in patients whose original dose was low ( $<.30 \mathrm{U} /$ day). ${ }^{1}$ Comparison of six unabsorbable carbohydrates or synthetic fibres showed guar to be the most effective in reducing postprandial glycaemia. ${ }^{4}$ Its high viscosity, however, precluded its use in long-term diabetic treatment until the recent development of a palatable guar crispbread. We have therefore looked at the effect on total urinary glucose output and fasting blood glucose concentrations of incorporating guar crispbread into both the metabolic ward and home-based diets of diabetics.

\section{Patients and methods}

We studied nine diabetics (four men and five women; see table I). After a preliminary three to four days in hospital seven of the patients began two five-day metabolic study periods, the order of which was randomised such that guar was added to the diets of three patients in the first period and to the diets of the remaining four in the last. During the preliminary days in hospital we reduced the patients' normal daily insulin dosages by a mean of $8 \mathrm{U}$ (table $\mathrm{I}$ ) and increased carbohydrate intake by $40-50 \mathrm{~g}$ daily to prevent hypoglycaemic episodes. ${ }^{2} 3$ In five cases the studies ran from Monday to Saturday morning, patients being replaced on their outpatient treatment at 